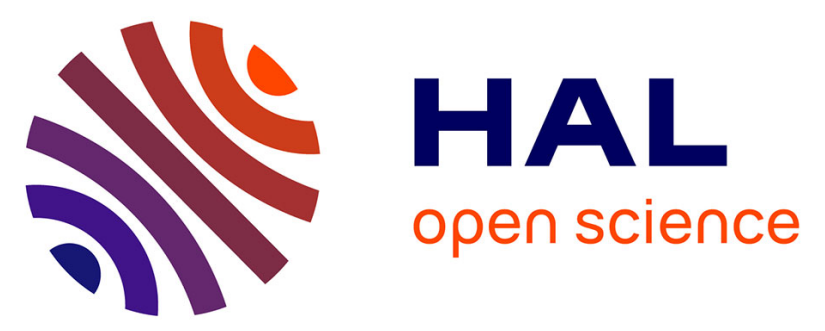

\title{
Bridging the Gap Between Requirements Engineering and Human-Computer Interaction
}

Achim Ebert, Shah Rukh Humayoun, Norbert Seyff, Anna Perini, Simone

Barbosa

\section{To cite this version:}

Achim Ebert, Shah Rukh Humayoun, Norbert Seyff, Anna Perini, Simone Barbosa. Bridging the Gap Between Requirements Engineering and Human-Computer Interaction. 1st and 2nd International Workshop on Usability- and Accessibility-Focused Requirements Engineering (UsARE 2012 / UsARE 2014), Jun 2012, Zurich, Switzerland. pp.3-7, 10.1007/978-3-319-45916-5_1 . hal-01631311

\section{HAL Id: hal-01631311 \\ https://hal.inria.fr/hal-01631311}

Submitted on 9 Nov 2017

HAL is a multi-disciplinary open access archive for the deposit and dissemination of scientific research documents, whether they are published or not. The documents may come from teaching and research institutions in France or abroad, or from public or private research centers.
L'archive ouverte pluridisciplinaire HAL, est destinée au dépôt et à la diffusion de documents scientifiques de niveau recherche, publiés ou non, émanant des établissements d'enseignement et de recherche français ou étrangers, des laboratoires publics ou privés. 


\title{
Bridging the Gap between Requirements Engineering and Human-Computer Interaction
}

\author{
Achim Ebert ${ }^{1}$, Shah Rukh Humayoun ${ }^{1}$, Norbert Seyff ${ }^{2}$, Anna Perini ${ }^{3}$, Simone D. J. \\ Barbosa $^{4}$ \\ ${ }^{1}$ Computer Graphics and HCI Group, University of Kaiserslautern, Germany \\ ${ }^{2}$ University of Applied Sciences and Arts Northwestern Switzerland and University of Zurich, \\ Switzerland \\ ${ }^{3}$ Fondazione Bruno Kessler - ICT, Italy \\ ${ }^{4}$ Pontifical Catholic University of Rio de Janeiro, Brazil \\ ${ }^{1}$ \{ebert, humayoun\}@cs.uni-kl.de, ${ }^{2}$ norbert.seyff@fhnw.ch, \\ ${ }^{3}$ perini@fbk.eu, ${ }^{4}$ simonelinf.puc-rio.br
}

\section{Introduction}

This book is intended to discuss important issues concerning Requirements Engineering (RE) and Human-Computer Interaction (HCI), especially the ones related to usability and accessibility. It is dedicated to observations, concepts, approaches, frameworks and practices that promote understanding, facilitating, and increasing the awareness of the role of usability and accessibility requirements and their proper integration into the requirement engineering process. The book is based on the two workshops on Usability- and Accessibility-focused Requirements Engineering (UsARE), which took place in 2012 and 2014. The first event, UsARE 2012 [8], was supported by IEEE and was held on June 04, 2012 in conjunction with the IEEE 34th International Conference on Software Engineering (ICSE 2012) in Zurich, Switzerland. The second event, UsARE 2014 [9], was supported by IEEE and IFIP and was held on August 25, 2014 in conjunction with the 22nd IEEE International Requirements Engineering Conference (RE 2014) in Karlskrona, Sweden. On both occasions, each submission was reviewed by at least three program committee members. This was followed by discussions amongst the organizers which led to a total number of 7 accepted papers for UsARE 2012 and 8 accepted papers for UsARE 2014. On both occasions, the workshop proceedings were published online by the IEEE Xplore Digital Library. The workshop summary and the results of the interactive session of the first event were published as a report in the ACM Software Engineering Notes in the issue of January 2013 [2].

There were 18 participants in UsARE 2012 and 22 participants in UsARE 2014. During the events, the authors presented their work; this was followed by intense discussions, in which participants actively took part. The last session in both events was dedicated to interactive discussions through the interactive group discussion strategy.

The idea of publishing the book with extended versions of the papers was born during the second event. All participants agreed that the topics definitely deserved to be explored further in order to give the related research communities in-depth outcomes of the research as workshop papers' lengths (4 pages for short and 7 pages for long) 
were not enough to present the ideas in much depth. We hope that the heavily extended papers in this book will help the readers to get a better insight on the research done by the participants of the two UsARE workshops.

\section{Goals and Issues}

High-level usability is acknowledged as a significant quality attribute of software products, while poor usability and inefficient design of the end product are common causes for failed software products $[1,6,7]$. Usability is defined by the International Organization for Standardization (ISO) as "the extent to which the product can be used by specified users to achieve specified goals with effectiveness, efficiency, and satisfaction in a specified context of use" [4]. The ISO/IEC Guidelines 71 define accessible design as "design focused on principles of extending standard design to people with some type of performance limitation to maximize the number of potential customers who can readily use a product, building or service" [5].

During the requirements analysis phase, software development teams may mainly focus on functional requirements. They may ignore system usability and accessibility concerns (such as effectivity, satisfaction, utility, learnability, memorability and visibility) due to multiple reasons, e.g., limited budget and resources. An early analysis of usability and accessibility requirements can guide the analysis at design-time; this results in a specification that provides more effective criteria to evaluate the software-tobe. Including system usability and accessibility requirements only at later development stages can be very costly [10]. Moreover, ignoring them in early stages could lead to delays in product development and deployment and can enhance the risks of project and software failure [3].

The focus of system usability and accessibility requirements is to ensure that the system is in compliance with the intended properties, which allows the users to use the system more efficiently and effectively in order to achieve their desired goals. Although requirements engineering has started to cope with system usability and accessibility issues along with other non-functional requirements, its efforts are still timid and systems often do not provide good usability and accessibility features. Therefore, it is important to properly integrate the system usability and accessibility requirements into the requirements engineering process and then to maintain them along other system requirements throughout the product lifecycle. This was the reason behind providing a suitable venue for discussions, which focused particularly on the integrated process and its effects on software development.

Overall, this book and the workshops previously held aim at creating awareness of the research and software development communities to focus a bit more on the following questions:

- How to incorporate system usability and accessibility requirements at early stages of RE;

- How to involve end users in the requirement phases in order to understand the usability and accessibility requirements more properly; 
- How to maintain the system usability and accessibility requirements throughout the development alongside other system requirements;

- How to manage and control requirements changes by assessing system usability and accessibility at run-time;

- How usability can improve dynamic elicitation of requirements from the endusers; and

- How requirements for accessibility and usability can be analyzed and managed in case of self-adaptive systems.

\section{The Articles in this Book}

This book consists of 10 chapters of which 9 are extended versions of the papers presented at the two UsARE events. Amongst them, 3 are extended versions of the papers presented at UsARE 2012 and 6 are extended versions of papers presented at UsARE 2014. There is one new chapter that was not presented at any of the previous events; however, it is added as authors are doing relevant work on the same topic. Each chapter was reviewed by at least 2 reviewers and an editor; to finalize the chapter, this was followed by a discussion between the editors. The chapters are organized into three sections according to their main focus: usability and user experience, accessibility and applications.

In the first section, four chapters provide methods and approaches regarding usability and user experience focused requirements engineering. First, Sutcliffe provides a method for analyzing emotion and motivation in requirements engineering using theories from psychology of emotion and motivation. Further, he describes the usage of agent technology in storyboards and scenario analysis and explains it with case studies from the health informatics. Then, Cindy et al. focus on personas as a tool for defining users' attributes and later as a document to be used throughout the entire development process. Drawing from their observations of five projects where personas were used, they highlight the opportunities and challenges that we could face while integrating personas within different activities of requirements engineering. After that, Kropp and Koischwitz introduce the role of On-site User Experience Consultant (osUX consultant) to support user-centered design integration with agile requirements engineering for fixed-price software development projects. Further, they highlight methods and practices of osUX consultancy to appropriately fit it into different agile RE process phases in order to avoid any conflict with other participating roles in the process. In the last part of this section, Xu and Read try to fill the gap between the human-computer interaction and requirements engineering within the scope of children or young people as the end users. They therefore focus on challenges and issues of gathering requirements from children and young people and suggest to treat children as research partners in this process.

The second section of the book concentrates on issues and their solutions when dealing with accessibility-related requirements engineering. There are three chapters in this section by several scholars from the area of accessibility. First, Ferati et al. provide the results of three workshops conducted with various stakeholders. They found that a one- 
solution-fits-all model is inadequate for the visually impaired community with respect to providing web experience. Evaluation results of their prototype built with eight adaption techniques indicate better performance with non-WCAG compliant websites compared to compliant ones. Then Belani et al. target media accessibility, information mobilization and consciousness for sensitive user groups. They highlight an augmentative requirements engineering framework, experience-driven from several projects and applications in Croatia, for augmentative and alternative communication services for sensitive user groups. In the last chapter of this section, Ludi targets teaching Mathematics and Science for visually impaired students using an Apple iPad as a tool. He presents strategies and techniques that were used for teaching different groups, distributed geographically and representing diverse constituencies. The results were used to model domain knowledge and to specify the target system's requirements.

The last section of the book comprises three chapters that discuss the application of usability- and accessibility-focused requirements engineering in different domains. First, De Silva et al. target users of mobile phones in developing countries. Their case study project was built for farmers in Sri Lanka with the purpose of helping them make more informed decisions. They describe how they combined different theories and methods taken from requirements engineering and human-computer interaction for gathering the requirements in this project. They found a systematic pattern of a combined RE and HCI process. Then Matsuno et al. propose a new conscious eye blink differentiation method taking into account individual differences, which can be used for developing eye blink user interfaces. Results of their evaluation suggest the feasibility of incorporating an automatic differentiation of conscious eye blinks using a conventional video camera. In the last chapter of this section, as well as of the book, Hu et al. describe how they designed a virtual community prototype for chronic diseases healthcare. This is done through getting requirements using questionnaires from healthcare recipients and interviewing healthcare providers. They suggest that using shared community platforms where all the stakeholders can be engaged would help in moderating the interoperability problems in healthcare systems.

Overall, these chapters cover requirements engineering from different perspectives of $\mathrm{HCI}$ and provide a comprehensive overview of the area to the readers. We hope you will find this book a useful bridge to fill the gap between RE and HCI. Finally, we are grateful for the time and efforts the authors and reviewers spent shaping this book in its current form. We are also grateful to the PC members, authors, and attendees for their contribution to the successful execution of the past two events.

Achim Ebert

Shah Rukh Humayoun Norbert Seyff

Anna Perini

Simone DJ Barbosa 


\section{$4 \quad$ References}

1. Anderson, J., Fleek, F., Garrity, K., and Drake, F. Integrating Usability Techniques into Software Development. IEEE Software, vol. 18, issue 1 (2001)

2. Catarci, T., Perini, A., Seyff, N., Humayoun, S. R., and Qureshi, N. A. 2013. First International Workshop on Usability and Accessibility focused Requirements Engineering (UsARE 2012): summary report. ACM SIGSOFT Software Engineering Notes, vol. 38, issue 1, 4346 (January 2013)

3. Charette, R. N. Why Software Fails. IEEE Spectrum, Vol. 42, Issue 9, 42-49, IEEE Press Piscataway, NJ, USA (September 2005)

4. ISO 9241-11: Ergonomic Requirements for Office Work with Visual Display Terminals (vdts). The international organization for standardization (1998)

5. ISO/IEC Guide 71Guidelines for Standards Developers to Address the Needs of Older Persons and Persons with Disabilities. International Organization for Standardization (ISO) (2001)

6. Landauer, T. K. The Trouble with Computers: Usefulness, Usability, and Productivity. The MIT Press (1996)

7. Norman, D. Why Doing User Observations First is Wrong. Interactions, 13:50-ff (July 2006)

8. Proceedings of the IEEE First International Workshop on Usability and Accessibility Focused Requirements Engineering (UsARE 2012), June 04, 2012, IEEE Catalog Number: CFP1203T-ART, ISBN: 978-1-4673-1846-4 (2012)

9. Proceedings of the IEEE 2nd International Workshop on Usability and Accessibility Focused Requirements Engineering, UsARE 2014, 25-25 August, 2014, Karlskrona, Sweden, IEEE Catalog Number: CFP1403T-ART ISBN: 978-1-4799-6352-2 (2014)

10. Souza, R. Design Accessible Sites Now, Forrester Report, http://www.forrester.com/ER/Research/Report/Summary/0,1338,11431,00.html (December 2001) 